\title{
Avaliação clínica e laboratorial dos efeitos dos catárticos salinos em equinos
}

Maristela de Cassia Seudo Lopes;, Tatyane Cristine Lomba da Silva, Natalia Dantas Fontes, Ezequiel Pereira Viana neto, Eduardo de Oliveira Costa, Abraão dos Santos Nunes, Gabriel Nunes Guimaraes, Leonidas Porto Farias Neto, Maria Carolina Soares de Sousa, Weslei Lima Gonçalves

Universidade Federal da Bahia (UFBA), Salvador, BA, Brasil

*Autor correspondente

e-mail: maris_vet@yahoo.com.br

\section{Resumo}

O tratamento clínico é a primeira escolha para as compactações do intestino grosso, pelo menos na maioria dos casos, e inclui suspensão da alimentação até a resolução da compactação, reidratação da ingesta, fármacos analgésicos e a utilização de laxantes e catárticos salinos como fármacos adjuvantes. Entretanto, as doses frequentemente utilizadas destes laxantes, principalmente nos equinos, são empíricas e usualmente vêm da medicina humana. Diante do exposto, objetivou-se investigar qual o efeito desses catárticos empregados na medicina equina para o tratamento das compactações intestinais e quais possíveis efeitos adversos. Para isso, foram utilizados sete equinos, fêmeas, SRD, com idade entre dois e cinco anos, peso entre 300 e 400kg. A escolha dos tratamentos foi realizada de maneira aleatória, sendo que todos os animais foram submetidos a todos os tratamentos em intervalos de 15 dias. A administração da fluidoterapia enteral (3l a cada 30 minutos/12 horas), bem como dos fármacos laxativos em única aplicação (DSS 10mg/kg, Sulfato de Magnésio 0,5g/kg e Hidróxido de Magnésio 2 litros), foram exclusivamente por sondagem nasogástrica. Foram avaliados o comportamento do animal perante qualquer desconforto gástrico e/ou diarreia, $\mathrm{FC}, \mathrm{f}, \mathrm{T}^{\circ} \mathrm{C}$, coloração de mucosas, motilidade intestinal, hemograma e quantidade de água nas fezes, nos seguintes momentos: M0 - Basal, M1, M2, M3 e M4 - uma, três, cinco e dez horas após a administração do fármaco, respectivamente. Não foi observado qualquer desconforto representado por dor visceral, hipermotilidade intestinal ou quadros de diarreia, bem como não houve alterações significativaa nos parâmetros clínicos e hematológicos avaliados. Entretanto, na quantificação de água nas fezes, em todos os tratamentos utilizados observouse aumento significativo de água presente nas fezes demonstrada pela análise bromatológica, porém sem diferença entre os tratamentos. Com isso, conclui-se que os usos dos catárticos salinos apresentam 
efeito significativo, umidificando as fezes, auxiliando na resolução de cólicas por compactação intestinal, quando administrados nas doses utilizadas neste estudo, não demonstrando efeitos adversos.

Palavras-chave: Cavalos. Cólica. Compactação. 